\title{
Experimental Investigation and Gaussian Process Emulation of Steel Skeleton Reinforced Concrete Behaviors in Split Hopkinson Pressure Bar Tests
}

\author{
Qiong-Li Wang and F. A. DiazDelaO \\ Institute for Risk and Uncertainty, University of Liverpool, Liverpool L69 7ZF, UK \\ Email: Q.L.Wang@liverpool.ac.uk, f.a.diazdelao@liverpool.ac.uk
}

\begin{abstract}
This paper conducts split Hopkinson pressure bar (SHPB) experiments to investigate the dynamic compressive properties of steel skeleton reinforced concrete (SSRC) materials. The SSRC specimens with the different volume fraction of steel range from 0 to $2.94 \%$ are investigated by conducting quasi-static and SHPB compression tests, respectively. In SHPB tests, the strain rate achieves from $30 \mathrm{~s}^{-1}$ to $100 \mathrm{~s}^{-1}$. The concrete matrix for all SSRC specimens is mixed to obtain a compressive strength of $45 \mathrm{MPa}$. The influences of different steel skeleton arrangements on the compressive strength, energy absorption, dynamic strain-stress relations, and failure modes are discussed and compared. The most important indicator, dynamic increase factor (DIF) relations of SSRC for compressive strength and Young's modulus are modelled probabilistically using Gaussian process (GP) emulation under the Bayesian framework. The corresponding performances are validated by individual prediction errors (IPE) diagnostics. The experimental results demonstrate that by adding certain types of steel skeleton into plain concrete, which gives a general better bonding property to concrete materials and increases the capacities of dynamic compressive strength, dynamic resistance and energy absorption.
\end{abstract}

Index Terms - Steel Skeleton Reinforced Concrete (SSRC), SHPB experiments, Gaussian Process (GP) Emulation, dynamic compression, Bayesian.

\section{INTRODUCTION}

In recent decades, increasingly severe challenges have arisen for modern concrete materials due to the construction of large-scale and complicated infrastructures, extreme service environments and multi-factor coupling actions [1,2]. These facilities not only have to bear normal design loads (quasi-static loads, creep loads) but also may be exposed to short strong dynamic loads such as explosions and impacts under some extreme conditions. Therefore, investigations of the dynamic mechanical behavior of concrete are important and essential to provide valuable information about the structural designs.

It is well known that dynamic concrete material properties are different from its quasi-static conditions. In

Manuscript received June 12, 2019; revised November 3, 2019; the early stage of research for concrete, the effect of strain rate on its compressive strength is at first drown researchers' attention. Abrams [3] conducted concrete compression experiments at a strain rate $\dot{\varepsilon}=2 \times 10^{-4} / \mathrm{s}$ and $\dot{\varepsilon}=8 \times 10^{-6} / \mathrm{s}$. The results suggested the compressive strength of concrete has strain rate sensitivity property. Bresler and Bertero [4] used hydraulic testing system to load the concrete specimens, the strain rate reached at $\dot{\varepsilon}=1 / s$. Hughes and Gregory [5] used drop weight impactor and its strain rate reached at $\dot{\varepsilon}=10 / \mathrm{s}$. D. Watstein [6] conducted drop weight impactor tests to cylindrical concrete specimen and found that in the range of strain rate at $\dot{\varepsilon}=10 / \mathrm{s}$, the dynamic compressive strength went up about $70 \%$. Malvern L E, et al. [7] conducted $\emptyset=76 \mathrm{~mm}$ SHPB tests to concrete specimens and results suggest the dynamic compressive strength at strain rate $\dot{\varepsilon}=118 / \mathrm{s}$ is 2.2 times larger to the value of static strength. A classical review of concrete material on dynamic behavior under high stain rate through various testing methods is given by Bischoff $\mathrm{P} \mathrm{H}$, et al. [8]. After that, the research into putting steel fibers as dispersed reinforcement for concrete (FRC) became popular since Roumaldi JP, et al. [9] first proposed the idea of combining steel fibers and concrete together. A classical review of the strain rate effects on FRC material properties by impact and impulsive loading is given by [10].

Most of the research on dynamic materials properties of FRC are based on experimental tests. The testing instruments include drop weight impactor [11], Split Hopkinson pressure bar [12] and detonation of explosives. FRC was found to be more strain rate sensitive than concrete and made with higher fibers content supposed to show larger strain rate sensitivity. Brandt [13] studied many types of fibers including high modulus steel, glass, carbon and asbestos of different shapes and in general, through fibers addition, the compressive strength was increased. $\mathrm{Xu}$, et al. [14] conducted drop weight impactor tests on concrete specimens with seven different types of fibers and conclude that the FRC with spiral shaped steel fibers is performed better than any other six fiber types in terms of ultimate compressive strength, post failure strength and energy absorption capacity. The energy absorption ability of concrete is also affected by steel fiber volume fraction as the strain rate is higher than 
100/s. The experimental results of Sun et al. [15] indicated that the strain-rate strengthening effect of concrete is reduced with the increase of steel fiber volume fraction. Hou et al. [16] investigated the dynamic compressive behavior of Reactive Powder Concrete (RPC) with 2\% and 5\% steel fiber at the strain rate range from $75 /$ s to $274 / \mathrm{s}$. It was concluded that the dynamic elastic modulus of concrete is sensitive to both steel fiber volume fraction and strain rate. Su et al. [17] observed that the dynamic behavior of ultra-high-performance concrete containing 3\% nanomaterial by weight has a strong dependency on the steel fiber. Soufeiani et al. [18] summarized previous researches about the effect of steel fiber shape and volume fraction on the dynamic behavior of concrete.

Despite the general literature review above, However, the research of Steel Skeleton Reinforced Concrete (SSRC) under impact loadings is limited. Therefore, in this paper, a series of experimental tests are processed to investigate mechanical properties of SSRC materials. Quasi-static and dynamic compression tests are carried out by using WWJ-2008B material testing machine and Split Hopkinson Pressure Bar (SHPB) system, respectively. All specimens are designed to have a dimension of $\varnothing 75 \times 35 \mathrm{~mm}$ ( $L / D$ is 0.5$)$ which is proposed by Bertholf LD and Karnes $\mathrm{CH}$ [19] to eliminate the effects of the axial inertia in high speed impact tests. Moreover, in all tests, grease is spread at both sides of specimens in order to minimize the end friction confinement due to the interaction between the specimen and instruments. For the arrangement of steel skeletons, the longitudinal steel is all $25 \mathrm{~mm}$ in length and arranged in a stratified array, the transverse steel adopts two layers of orthogonal arrangement, the space between the layers is $15 \mathrm{~mm}$, the diameter of steel is 2 $\mathrm{mm}$ in Fig. 1.

In this paper, three different longitudinal steel arrangements are considered: $0,3 \times 3,3 \times 4$ which have a volume fraction of steel $0.0 \%, 1.91 \%$ and $2.94 \%$ respectively. The influences of different longitudinal steel arrangements for SSRC specimens under quasi-static tests are studied. It is found that the peak stress, the post-peak load bearing capacity, the energy absorption capacity is improved by increasing the volume fraction of steel. For the dynamic compression tests, the SHPB tests achieve strain rate from $30 \mathrm{~s}^{-1}$ to $100 \mathrm{~s}^{-1}$. The stress/strain equilibrium is examined, the failure modes are obtained and compared. Dynamic stress-strain curves and energy absorption capacities under different strain rate are captured and compared. Strain rate sensitivity on the compressive strength is discussed, DIF (Dynamic Increase Factor) for compressive strength and Young's modulus relations for SSRC specimens are constructed probabilistically through Gaussian Process (GP) emulation in Bayesian framework.

\section{EXPERIMENTAL PROGRAM}

\section{A. Specimens}

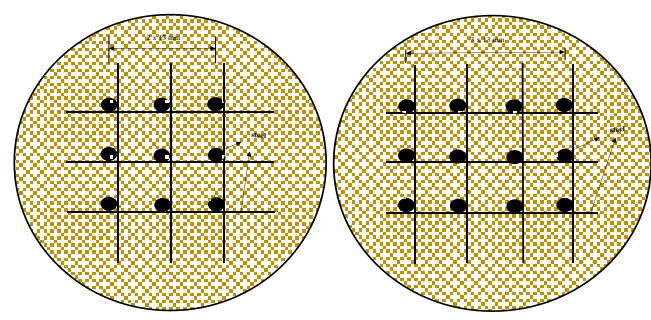

Figure 1. SSRC33 and SSRC34

The cement used to prepare the specimens is the ordinary Portland cement, the maximum coarse aggregate is $10 \mathrm{~mm}$, the detailed mixtures for concrete are given in Table I. All specimens are designed to have a dimension of $\emptyset 70 \times 35 \mathrm{~mm}(L / D$ is 0.5$)$ and mixed into steel molds and ensure all the steel skeletons are not exposed to air. The specimens are being carefully cured for 24 hours after demolded and then placed into normal temperature water for 28 days curing. After 28 days, both end surfaces of specimens are smoothed, dried and tested. A total number of 60 specimens are prepared for quasi-state and SHPB tests, with 20 specimens for concrete, SSRC33, SSRC34, respectively. The prepared specimens and a typical steel skeleton of $3 \times 3$ is given in Fig. 2. The relations of longitudinal steel array and volume fraction of steel are given in Table II.

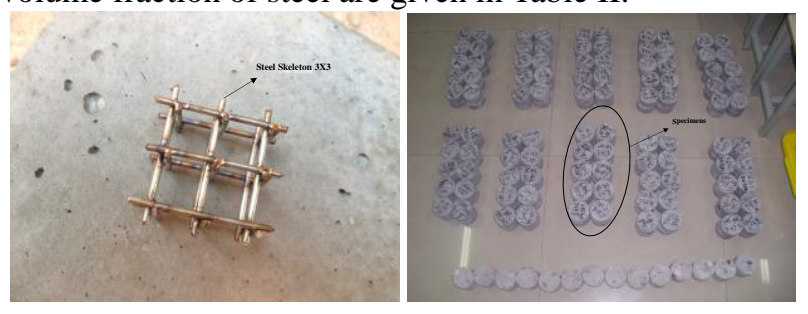

Figure 2. Steel skeleton and specimens

TABLE I. MiX PROPORTIONS OF SPECIMENS

\begin{tabular}{ccccccccc}
\hline \multirow{2}{*}{ Mixes (\%) } & \multirow{2}{*}{ W/C } & \multirow{2}{*}{$\mathrm{V}_{\mathrm{f}}(\%)$} & \multicolumn{6}{c}{ Mix proportions $\left(\mathrm{kg} / \mathrm{m}^{3}\right)$} \\
\cline { 4 - 9 } & & & Water & Cement & $10 \mathrm{~mm}$ & $7 \mathrm{~mm}$ & $5 \mathrm{~mm}$ & sand \\
\hline Concrete & 0.36 & 0 & 200 & 556.2 & 567.1 & 425.25 & 141.95 & 509.6 \\
SSRC33 & 0.36 & 1.91 & 200 & 556.2 & 567.1 & 425.25 & 141.95 & 509.6 \\
SSRC34 & 0.36 & 2.94 & 200 & 556.2 & 567.1 & 425.25 & 141.95 & 509.6 \\
\hline W/C: water to cement ratio. & & & & & & \\
V & (f: volume fraction of steel. & & & & &
\end{tabular}

TABLE II. LONGITUDIBNAL STEEL RATIO

\begin{tabular}{cc}
\hline Longitudinal steel array & $\mathrm{V}_{\mathrm{f}}(\%)$ \\
\hline Concrete & 0 \\
SSRC33 & 1.91 \\
SSRC34 & 2.94 \\
\hline
\end{tabular}

$\mathrm{V}_{\mathrm{f}}$ : volume fraction of steel. 
B. Quasi-static and SHPB Dynamic Compression Tests
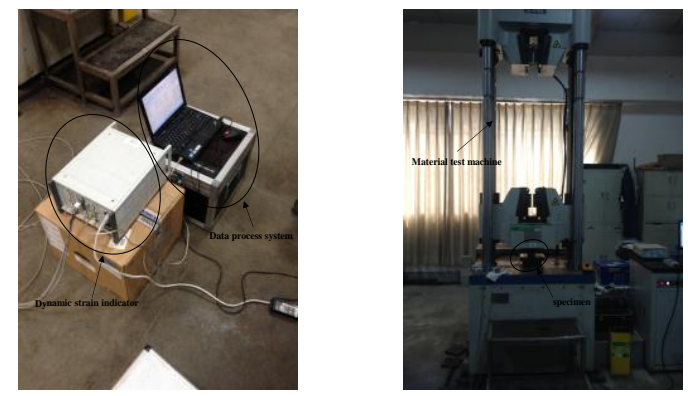

Figure 3. Quasi-static compression experiment preparation

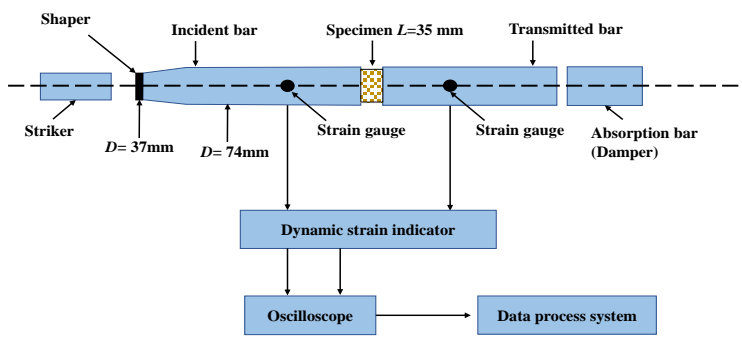

Figure 4. SHPB compression experiment preparation

The quasi-static compression tests were conducted by using WWJ-2000B material test machine at national high-speed railway construction technology laboratory in Central South University (CSU) in China shown in Fig. 3. The WWJ-2000B material test machine used a closed circuit electro-hydraulic system to make sure the load could be compensated quickly to guarantee the whole testing process stable. The vertical loads and displacement versus time were recorded by the data processing system. In each test, the grease was spread on the interfaces between specimens and instruments to minimize the influence of friction.

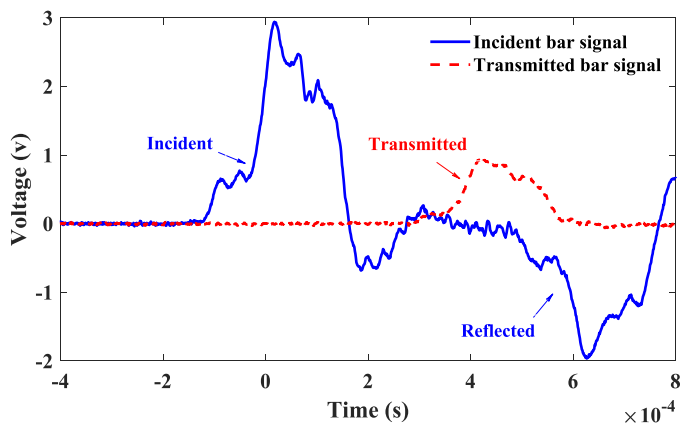

Figure 5. SHPB signals of SSRC34

The dynamic impact compression tests were conducted by using SHPB test system in HeFei University of Technology. Its setups are shown in Fig. 4. The SHPB system was a variable cross-section type test system with $\emptyset 74 \mathrm{~mm}$. The striker bar had a diameter of $\varnothing 37 \mathrm{~mm}$ and length of $800 \mathrm{~mm}$, the incident bar was a variable cross-section bar, the large side had a diameter of $\emptyset 74 \mathrm{~mm}$ and the small side had a diameter of $\varnothing 37 \mathrm{~mm}$.
The transition length from small side to large side was $420 \mathrm{~mm}$, the overall length of incident bar was $3061 \mathrm{~mm}$, the length of transmission bar was $1797 \mathrm{~mm}$ with a diameter of $\varnothing 74 \mathrm{~mm}$.

Before doing SHPB tests, a waveform shaper was used, which had the power to initiate a half-sine loading waveform which could eliminate violent oscillation and dispersion is illustrated in Fig. 5. Strain gauges were placed at the middle surface of incident and transmission bars. The bars were made of stainless steel with density $7850 \mathrm{~kg} / \mathrm{m}^{3}$, Young's modulus $210 \mathrm{GPa}$, Poison's ratio 0.25 and the elastic wave velocity was $5172 \mathrm{~m} / \mathrm{s}$.

In order to eliminate errors as much as possible, each specimen was carefully prepared by smoothing and grinding to guaranty both two sides were parallel. Moreover, the roughness on surfaces was controlled to be less than $0.02 \mathrm{~mm}$.

\section{TEST RESULTS AND DISCUSSION}

\section{A. Quasi-static Compression Tests}

The typical results of Concrete, SSRC33 and SSRC34 under quasi-static loadings are given in Table III. It is obvious that the compressive strength is improved when the steel skeletons are being inserted into the specimens.

TABLE III. MATERIAL PROPERTIES IN QUASI-STATIC CONDITION

\begin{tabular}{lccc}
\hline & $\begin{array}{c}\text { Dry density } \\
\left(\mathrm{kg} / \mathrm{m}^{3}\right)\end{array}$ & $\begin{array}{c}\text { Compressive } \\
\text { strength (MPa) }\end{array}$ & $\begin{array}{c}\text { Young's } \\
\text { modulus } \\
(\mathrm{GPa})\end{array}$ \\
\hline Concrete & 2250 & 47.52 & 31.44 \\
SSRC33 & 2279 & 54.68 & 32.35 \\
SSRC34 & 2293 & 56.03 & 32.76 \\
\hline
\end{tabular}

When the arrangement of steel skeletons changes from $3 \times 3$ to $3 \times 4$, the increment in compressive strength is not very outstanding. Mander JB, et al. [20] defined expression to describe the energy absorption capacity of specimens:

$$
E=\int \sigma d \varepsilon
$$

where $\mathrm{E}$ is the energy absorption index, $\sigma$ is stress and $\varepsilon$ is stress.

This equation uses a simple integration using trapezoidal rule and the corresponding energy capacity of specimens are computed in Fig. 6.

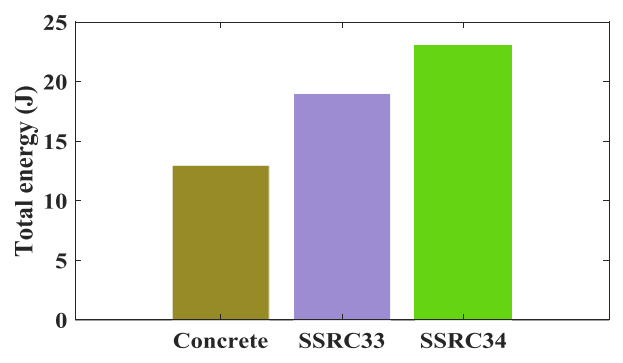

Figure 6. Energy absorption capacity 


\section{B. $\quad$ SHPB Compression Tests}

The SHPB compression tests were conducted for the specimens: Concrete, SSRC33 and SSRC34. The computation theory is based on one-dimension stress wave propagation theory. The equations below were used to calculate the stress, the strain and the strain ratio of specimens [21].

$$
\left\{\begin{array}{c}
\sigma_{s}(t)=\frac{E A}{A_{s}} \varepsilon_{t}(t) \\
\varepsilon_{S}(t)=\frac{2 C_{0}}{l_{s}} \int_{0}^{t}\left[\varepsilon_{i}(t)-\varepsilon_{t}(t)\right] d t \\
\dot{\varepsilon}_{s}(t)=\frac{2 C_{0}}{l_{s}}\left[\varepsilon_{i}(t)-\varepsilon_{t}(t)\right]
\end{array}\right.
$$

where E, A are Young's modulus and cross-section area of pressure bars. $A_{S}$ and $l_{s}$ are the cross-section area and length of test specimens. $\varepsilon_{i}$ and $\varepsilon_{t}$ are the measured incident and transmitted strain data. $\mathrm{C}_{0}$ is elastic wave velocity of pressure bars.

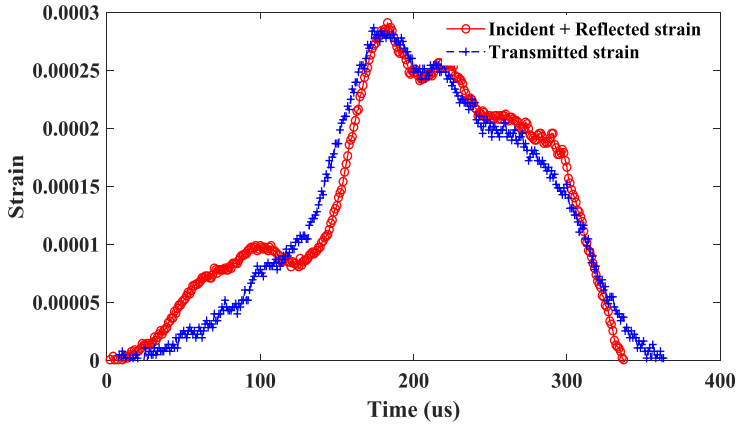

Figure 7. Stress/Strain equilibrium verification

A typical signal from SHPB tests can be seen in Fig. 5. In the tests, even with the help of waveform shaper, it is hard to find a relative stability region used as an average strain rate when the peak value in stress history is used. This is caused by different sources of uncertainty such as tested materials, geometrical properties et al [22]. For this case, the value of strain rate was chosen by the peak stress used as the strength.

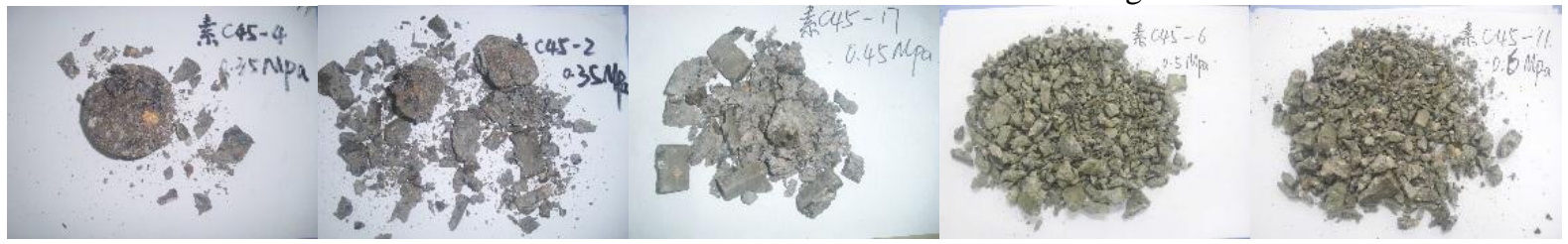

Figure 8. Failure patterns of concrete

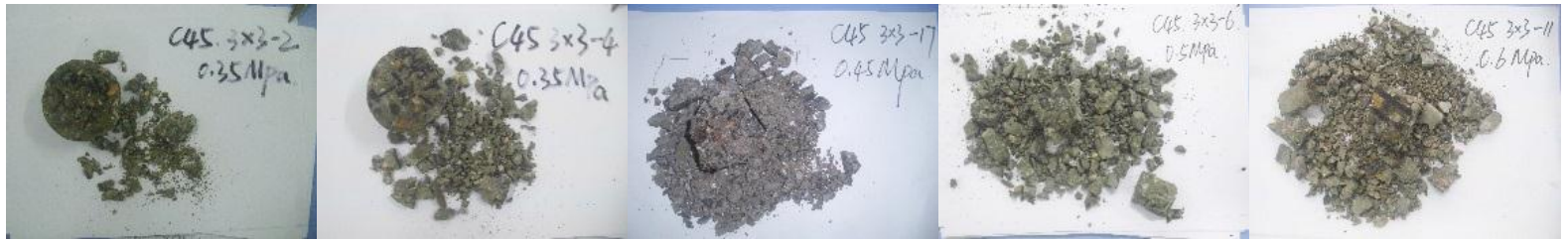

Figure 9. Failure patterns of SSRC33
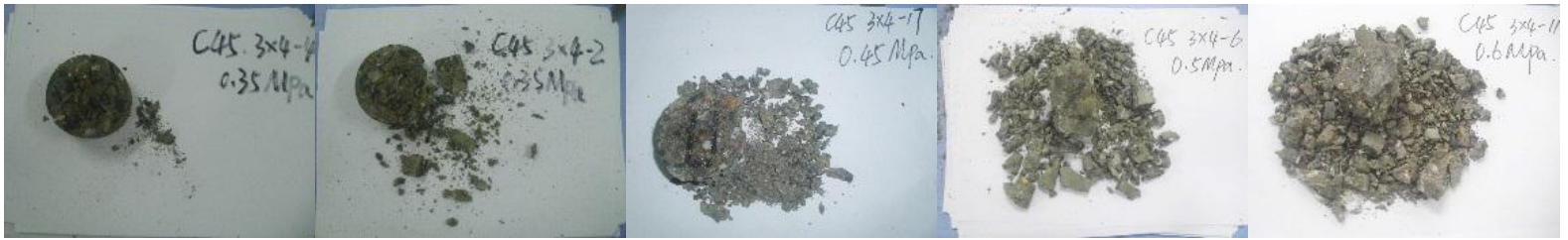

Figure 10. Failure patterns of SSRC34

During the SHPB tests, it is vital to check the longitudinal stress/strain equilibrium that needed to be achieved [23]. In this paper, (3) is used to check the dynamic stress/strain equilibrium. Moreover, Fig. 7 gives an example of signals taken from SSRC33 for stress/strain equilibrium checkout. The time lags have already been moved for clear comparison. It can be seen from Fig. 7 that the stress/strain equilibrium status is achieved which means the results of SHPB impact compression tests are proved to be validated.

$$
\varepsilon_{i}(t)+\varepsilon_{r}(t)=\varepsilon_{t}(t)
$$

The failure patterns of specimens under SHPB tests are shown from Fig. 8 to Fig. 10. In Fig. 8, the failure patterns for concrete go through edge broken, slightly broken, broken, slight grinding and grinding 5 stages as the strain rate increased. In Fig. 9, the failure patterns for SSRC33 go through edge broken, slightly broken, slight grinding, half grinding and grinding 5 stages and in Fig. 10, the failure patterns for SSRC34 go through almost unbroken, edge crack, half broken, broken and grinding 5 stages with corresponding the same strain rate levels.

The observations demonstrate the toughness of tested specimens is improved with steel skeleton engaged in from Concrete to SSRC34. A steel skeleton is quite effective to protect the concrete in the core from broken to even grindings. And this effect is enhanced further with the steel skeleton changes from $3 \times 3$ to $3 \times 4$. 


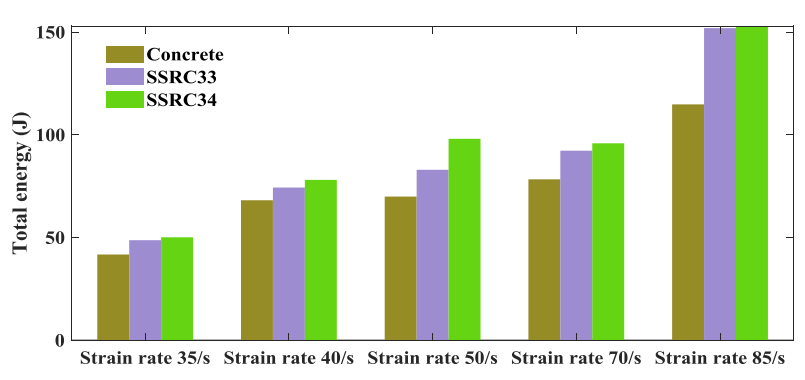

Figure 11. SHPB energy absorption capacity

On the other hand, the failure patterns of specimens are found to change with the strain rate varies. When the strain rate is relatively low, the damage pattern is not very serious. When the strain rate is relatively high, broken fragments or even broken, grindings can be observed.
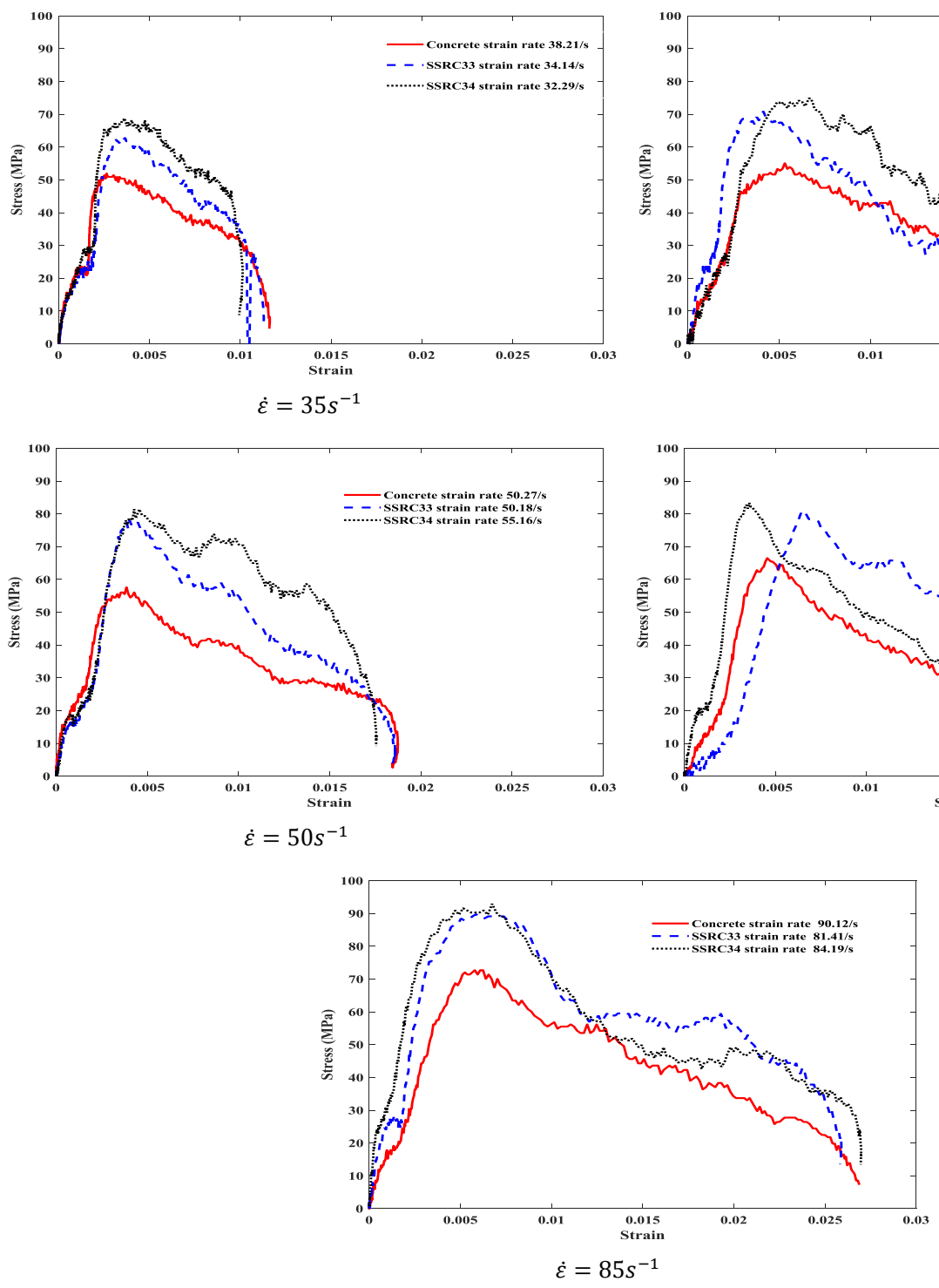

Figure 12. Stress-strain curves under different strain rates
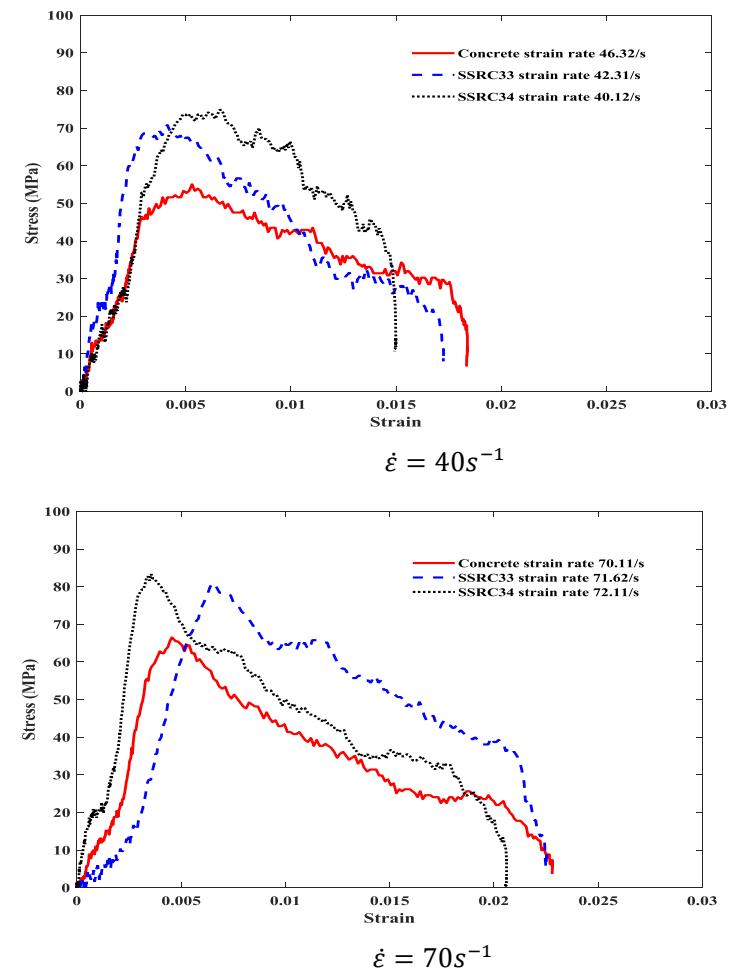

Equation (1) is also used to describe the capabilities of energy absorption for specimens under certain strain rate levels in SHPB tests. In Fig. 11, when the strain rate is less than $50 s^{-1}$, the energy absorption by specimens is increased since the steel skeleton changes from $3 \times 3$ to $3 \times 4$. When strain rate reached at $50 s^{-1}$ and $70 s^{-1}$, the ability of energy absorption for SSRC33 and SSRC34 improved not very much. When the strain rate is reached at around $85 s^{-1}$, all the specimens increased a lot of energy absorption and the absorption values of SSRC33 and SSRC34 almost reach at the same stage around $155 \mathrm{~J}$. Fig. 12 shows the stress-strain curves of all specimens under 5 different strain rate levels. Generally, the energy absorption capacities, maximum compressive strain is largely enhanced by the insertion of steel skeletons.

$\dot{\varepsilon}=70 s^{-1}$ 


\section{RATE EFFECTS AND GPS EMULATION OF DIFS ON COMPRESSIVE STRENGTH AND YOUNG'S MODULUS}

The effect of strain rate on compressive strengths of all specimens is illustrated in Fig. 13. The Dynamic Increase Factor (DIF) for compressive strength is calculated by the dynamic compressive strength normalized by the average static compressive strength of the same type of specimen listed in Table III.

TABLE IV. DIFS SUMMARY FOR CONCRETE

\begin{tabular}{ccc}
\hline Strain rate $(1 / \mathrm{s})$ & $\begin{array}{r}\text { DIF for compressive } \\
\text { strength }\end{array}$ & $\begin{array}{c}\text { DIF for Young's } \\
\text { Modulus }\end{array}$ \\
\hline $1 \times 10^{-3}$ & 0.98 & 0.99 \\
38.21 & 1.10 & 1.03 \\
39.66 & 1.14 & 0.98 \\
41.05 & 1.12 & 1.03 \\
46.32 & 1.18 & 1.01 \\
46.78 & 1.21 & 1.00 \\
47.40 & 1.19 & 1.02 \\
50.27 & 1.22 & 1.04 \\
51.66 & 1.34 & 1.06 \\
53.07 & 1.28 & 1.04 \\
70.11 & 1.41 & 1.08 \\
72.67 & 1.43 & 1.07 \\
73.06 & 1.47 & 1.09 \\
90.12 & 1.52 & 1.11 \\
91.67 & 1.49 & 1.10 \\
\hline
\end{tabular}

Moreover, the DIF results of all specimens for compressive strength and Young's modulus are listed from Table IV to Table VI. From Fig. 13, it is obvious that the compressive strength of all specimens is sensitive to strain rate. Compared with the scatters values of DIF on Concrete specimens, the SSRC33, SSRC34 show a similar strain rate sensitivity trend and indicate more rate sensitive than the Concrete under SHPB tests.

TABLE V. DIFS SUMMARY FOR SSRC33

\begin{tabular}{ccc}
\hline Strain rate $(1 / \mathrm{s})$ & $\begin{array}{r}\text { DIF for compressive } \\
\text { strength }\end{array}$ & $\begin{array}{c}\text { DIF for Young's } \\
\text { Modulus }\end{array}$ \\
\hline $1 \times 10^{-3}$ & 0.99 & 1.01 \\
34.14 & 1.17 & 1.18 \\
34.99 & 1.20 & 1.19 \\
36.07 & 1.24 & 1.16 \\
42.31 & 1.30 & 1.20 \\
42.54 & 1.29 & 1.24 \\
43.66 & 1.34 & 1.26 \\
50.18 & 1.42 & 1.27 \\
50.66 & 1.40 & 1.30 \\
52.17 & 1.44 & 1.31 \\
71.62 & 1.52 & 1.33 \\
72.03 & 1.54 & 1.30 \\
73.44 & 1.51 & 1.35 \\
81.41 & 1.64 & 1.36 \\
82.07 & 1.62 & 1.34 \\
\hline
\end{tabular}

The effect of strain rate on Young's Modulus of all specimens is illustrated in Fig. 14. The dynamic increase factor (DIF) for Young's Modulus is calculated by Young's Modulus under dynamic compression normalized by the average static Young's Modulus of the same type of specimen listed in TABLE III. From Fig. 14, compared to Concrete, the DIFs for the SSRC33 and SSRC34 are slightly higher and seem to follow a similar trend.

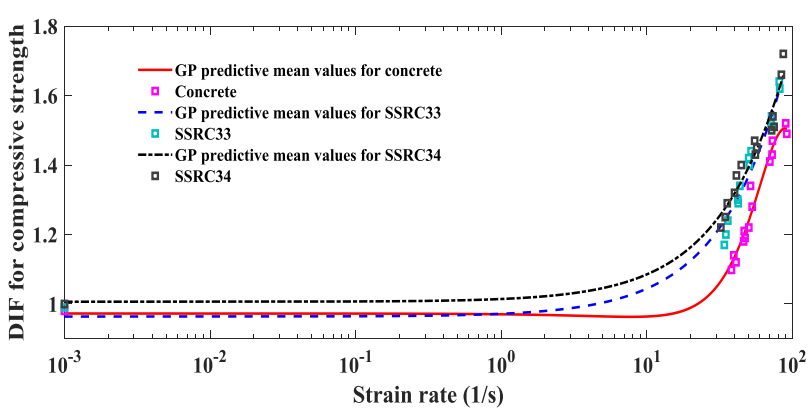

Figure 13. DIFs for compressive strength

Finding the best-fit DIF relations for the compressive strength and Young's modulus of SSRC specimens with different steel skeletons is necessary. Because these relations can be used to estimate DIF of SSRC in numerical prediction of SSRC structure responses to other high-rate loadings. Researchers such as $\mathrm{Xu} \mathrm{Z}$, et al. [24], Y. Hao, et al. [25] used deterministically polynomial fitting techniques to do the curve fitting.

However, these methodologies are limited in the sense that, being deterministic, are unable to account for the uncertainty present in the experiment and due to the fact that it is expensive to run such experiments.

TABLE VI. DIFS SUMMARY FOR SSRC34

\begin{tabular}{ccc}
\hline Strain rate $(1 / \mathrm{s})$ & $\begin{array}{r}\text { DIF for compressive } \\
\text { strength }\end{array}$ & $\begin{array}{c}\text { DIF for Young's } \\
\text { Modulus }\end{array}$ \\
\hline $1 \times 10^{-3}$ & 1 & 0.98 \\
32.29 & 1.22 & 1.27 \\
34.66 & 1.25 & 1.31 \\
35.77 & 1.29 & 1.30 \\
40.12 & 1.32 & 1.29 \\
41.33 & 1.37 & 1.32 \\
44.62 & 1.40 & 1.33 \\
55.16 & 1.47 & 1.35 \\
55.77 & 1.43 & 1.32 \\
57.03 & 1.45 & 1.34 \\
72.11 & 1.50 & 1.44 \\
73.66 & 1.54 & 1.46 \\
75.03 & 1.51 & 1.42 \\
84.19 & 1.66 & 1.48 \\
86.75 & 1.72 & 1.49 \\
\hline
\end{tabular}

Gaussian process (GP) emulation is a modelling process based on statistical learning theory which has drawn a growing interest in solving uncertainty quantification problems, computationally intensive problems in various fields such as climate prediction [26], deterministic structural dynamics [27], stochastic structural dynamics [28], test crash modelling [29] and among many others. GP emulation is constructed in a Bayesian framework. A small set of measured data values is treated as training data used to update the prior beliefs about the simulation output. These prior beliefs take the form of a Gaussian stochastic process. After conditioning on the training data and updating, the mean values of the resulting posterior distribution provides a fast approximation to the outputs at any untried inputs. 


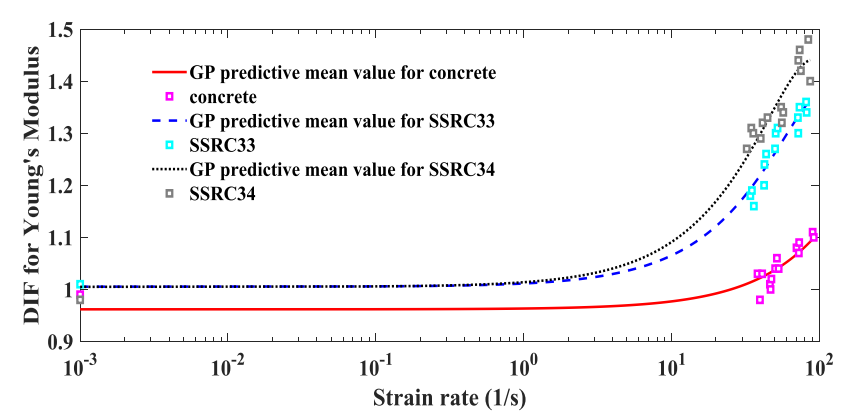

Figure 14. DIFs for Young's modulus

Let $f(\mathbf{x})$ be a simulator output as a function of its inputs which could be expressed as

$$
f(\mathbf{x})=h(\boldsymbol{X})^{T} \beta+Z(\boldsymbol{X})
$$

where $h(\boldsymbol{X})^{\boldsymbol{T}}$ is a vector of known functions and $\beta$ is a vector of unknown coefficients, $Z(\boldsymbol{X})$ is a stochastic process with mean zero and covariance $\sigma^{2} k\left(\boldsymbol{X}, \boldsymbol{X}^{\prime} ; \psi\right)$. $h(\boldsymbol{X})^{\boldsymbol{T}}$ should express any expert opinions about the form of the simulator outputs and together with $\beta$ reflects its overall trend. $\sigma^{2}$ is a scalar parameter, $k\left(\boldsymbol{X}, \boldsymbol{X}^{\prime} ; \psi\right)$ is a known correlation function and $\psi$ are parameters specifying the smoothness of the output.

Utilizing the formulation of GP emulation, a posterior distribution for the unknown output could be constructed, conditioned on some simulator runs with outputs $\mathbf{y}$ and the estimated parameter values, $\widehat{\boldsymbol{\theta}}=\left(\hat{\beta}, \widehat{\sigma}^{2}, \widehat{\psi}\right)$. It can be shown that in [30], the posterior distributions at new unobserved set of inputs, $\boldsymbol{X}^{*}$, has a form of multivariate Gaussian distribution:

$$
f\left(\boldsymbol{X}^{*}\right) \mid \mathbf{y}, \widehat{\boldsymbol{\theta}} \sim \mathcal{N}\left(M\left(\boldsymbol{X}^{*}\right), C\left(\boldsymbol{X}^{*}, \boldsymbol{X}^{* \prime}\right)\right)
$$

With posterior predictive mean function:

$$
M\left(\boldsymbol{X}^{*}\right)=\widehat{\beta}+\boldsymbol{k}\left(\boldsymbol{X}^{*}\right)^{T} \boldsymbol{K}^{-1}(\boldsymbol{y}-1 \hat{\beta})
$$

And the posterior predictive covariance function:

$$
C\left(\boldsymbol{X}^{*}, \boldsymbol{X}^{*^{\prime}}\right)=\widehat{\sigma}^{2}\left(k\left(\boldsymbol{X}^{*}, \boldsymbol{X}^{*^{\prime}}\right)-\boldsymbol{k}\left(\boldsymbol{X}^{*}\right)^{T} \boldsymbol{K}^{-1} \boldsymbol{k}\left(\boldsymbol{X}^{*^{\prime}}\right)\right)
$$

where $\boldsymbol{K} \in \mathbb{R}^{n \times n}, \boldsymbol{K}_{\boldsymbol{i j}}=k\left(\boldsymbol{X}_{\boldsymbol{i}}, \boldsymbol{X}_{\boldsymbol{j}}\right), \boldsymbol{k}\left(\boldsymbol{X}^{*}\right) \in \mathbb{R}^{n}$.

Since the training is done not by running a model, but by observing experiments, then a noise term has to be added to the covariance matrix. Therefore, the output $y$ is generated with Gaussian white noise: $\mathrm{y}=f+\epsilon, \epsilon \sim \mathcal{N}\left(0, \sigma_{\text {noise }}^{2}\right)$. The corresponding covariance matrix in (6) and (7) becomes $(\boldsymbol{K}+$ $\left.\sigma_{\text {noise }}^{2} \boldsymbol{I}\right)^{-1}$.

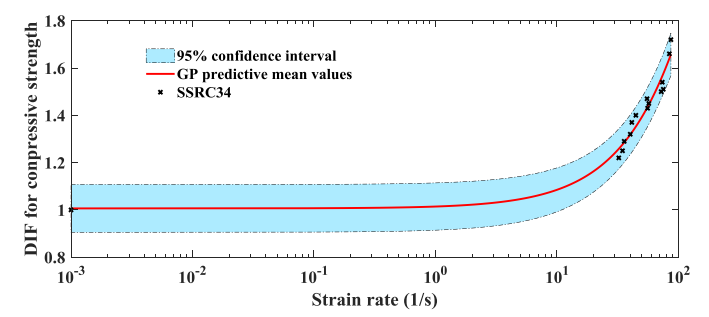

Figure 15. GPs emulation of DIFs for compressive strength in SSRC34

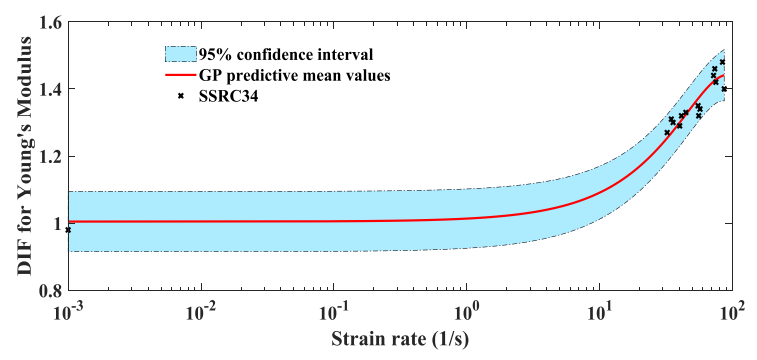

Figure 16. GPs emulation of DIFs for Young's modulus in SSRC34

In order to train the emulator, 10 measured points were selected across the input domain according to J. Loeppky, et al. [31] who justify that the number of measured training points, $\mathrm{n}$, that is required depends on the number of uncertain input dimensions $\theta$ and an practical rule is that $\mathrm{n}$ should be about $10 \times \theta$.

Following above, GP emulators for DIF relations to the compressive strength and Young's modulus of the plane concrete, SSRC33 and SSRC34 are constructed. The GP predictive mean curves and corresponding predictive $95 \%$ confidence intervals of selected SSRC34 for compressive strength and Young's modulus are shown in Fig. 15 and Fig. 16.

In order to validate the well-trained GP model to find whether the updated emulator is accurate enough to present the data points. Bastos and O' Hagan [32] proposed a diagnostic for GPs model called individual prediction errors (IPE) which has the form:

$$
\varrho_{j}\left(y^{*}\right)=\frac{\boldsymbol{y}_{j}^{*}-\mathbb{E}\left[f\left(\boldsymbol{X}_{\boldsymbol{i}}^{*}\right) \mid \mathbf{y}\right]}{\widehat{\sigma} \sqrt{\mathbb{v}\left[f\left(\boldsymbol{X}_{\boldsymbol{i}}^{*}\right) \mid \mathbf{y}\right]}}
$$

For a reliable GP emulator, the IPE should follow a Student-t distribution and $95 \%$ of validated points located in the interval $[-2,2]$. The IPE diagnostics is used in this paper to validate the GP emulator. Fig. 17 and Fig. 18 shows IPEs of selected SSRC34 for compressive strength and Young's modulus with only 5 points to validate since making such experiments is expensive. It can be observed that the validated points lie in the desired region, which illustrates the well-trained GP emulator model could be used to estimate DIFs of SSRC in numerical prediction of SSRC structure responses to other different impact loadings. It should be noted that obtaining more validation points means conducting more experiments, $\mathrm{w}^{1} \cdot \mathbf{1}^{\prime} \cdot$

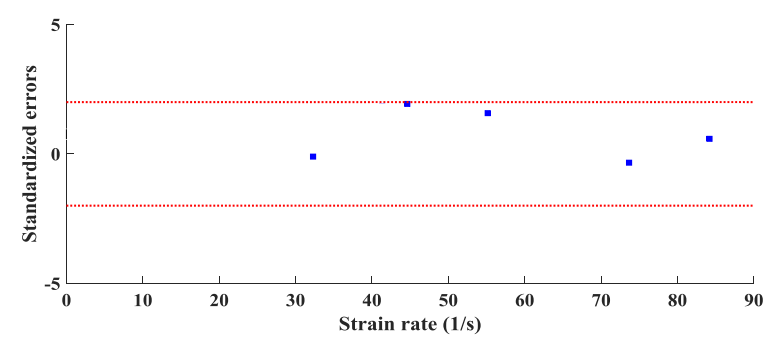

Figure 17. IPE of SSRC34 for compressive strength 


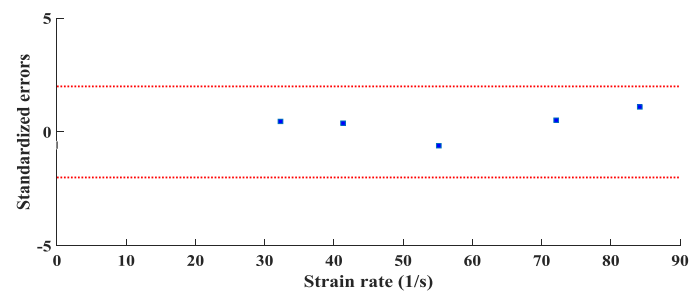

Figure 18. IPE of SSRC34 for Young's modulus

\section{CONCLUSIONS}

This paper presents some useful results from quasi-static and SHPB tests for three types of specimens: Concrete, SSRC33 and SSRC34. The plain concrete specimens are regarded as control samples for comparison. It is observed that under quasi-static tests, the compressive strength, energy absorption and post-peak load bearing capacity are improved from Concrete to SSRC34. The toughness of tested specimens is improved with steel skeleton engaged in from SSRC33 to SSRC34. In addition, a steel skeleton is quite effective to protect the concrete in the core from broken to even grindings. For SHPB tests, the overall stress-strain curves of all specimens under 5 different strain rate levels generally indicate that the energy absorption capacities, maximum compressive strain are large enhanced by the insertion of steel skeletons compared to the plain concrete. A modelling technique called Gaussian process (GP) emulation is employed to obtain the relations of DIFs for compressive strength and Young's modulus from different strain rates. The well-trained GP model is validated by individual prediction errors (IPE) diagnostics. DIFs of the compressive strength and Young's modulus show increasing rate sensitivity to strain rate from Concrete to SSRC34. In addition, more experimental tests are suggested to conduct in the future to have more validation points to validate the trained GP emulators and considering other kinds of arrangements of steel skeletons in order to have a more comprehensive understanding of the dynamic mechanical behaviors of this material is also recommended.

\section{CONFLICT OF INTEREST}

The authors declare no conflict of interest.

\section{AUTHOR CONTROBUTIONS}

All the authors made significant contributions to the work. Qiong-Li Wang and F. A. DiazDelaO conceived this study; Qiong-Li Wang simulated and analyzed the data; F. A. DiazDelaO contributed analysis tools; Qiong-Li Wang wrote the paper; F. A. DiazDelaO reviewed the manuscript for scientific contents.

\section{ACKNOWLEDGMENT}

The first author acknowledges the support from The China Scholarship Council (CSC) and The University of Liverpool

\section{REFERENCES}

[1] B. G. Han, X. Yu, J. P. Ou, in: Self-Sensing Concrete in Smart Structures, Publisher: Elsevier, 2014, p. 385.

[2] B. G. Han, L. Q. Zhang, J. P. Ou, Smart and Multifunctional Concrete toward Sustainable Infrastructures, Publisher: Springer, 2017, p. 400.

[3] D. A. Abrams, "Effect of rate of application of load on the compressive strength of concrete," Journal of ASTM International, vol. 17, no. 2, pp. 364-377, 1917.

[4] B. Bresler, V. V. "Bertero influence of high strain rate and cyclic loading of unconfined and confined concrete in compression," in Proc. Second Canadian Conference on Earthquake Engineering, Hamilton, Ontario, 1975. P, 1-13.

[5] B. P. Hughes, R. Gregory, "Concrete subjected to high rates of loading in compression," Acta Mechanic, vol. 24, no. 78, pp. 25-36, 1972.

[6] D. Watstein, "Effect of straining rate on the compressive concrete," ACI Journal, vol. 49, no. 8, pp. 729-744, 1953.

[7] L. E. Malvern, D. A. Jenkins, T. X. Tang, et al. "Dynamic compressive testing of concrete," in Proc. 2nd Symposium on the Interaction of Non-nuclear Munitions with Structures, Florida : Us Department of Defense, 1985, 194-199.

[8] P. H. Bischoff, S. H. Perry, "Compressive behavior of concrete at high strain rates," Materials and Structures, vol. 144, no. 24, pp. 425-450, 1991.

[9] J. P. Roumaldi, G. B. Batson, "Mechanics of crack arrest in concrete," J. Eng. Mech. Div. ASCE, 1963, 89(EM3), pp. 147-68.

[10] W. Suaris, S. P. Shah, "Strain-rate effects in fiber-reinforced concrete subjected to impact and impulsive loading," Composites, pp. 153-159, 1982.

[11] C. V. Srinivasa, A. Arifulla, N. Goutham, T. Santhosh, H. J. Jaeethendra, R. B. Ravikumar, et al. "Static bending and impact behavior of areca fibers composites," Mater Des, vol. 32, 2469-75, 2011.

[12] T. S. Lok, P. J. Zhao, G. Lu, "Using the split Hopkinson pressure bar to investigate the dynamic behavior of SFRC," Mag Concr Res, pp. 183-191, 2003.

[13] A. M. Brandt, "Fiber reinforced cement-based (FRC) composites after over 40 years of development in building and civil engineering," Compos Struct, vol. 86, pp. 3-9, 2008.

[14] Z. Xu, H. Hao, H. N. Li, "Experimental study of dynamic compressive properties of fibre reinforced concrete material with different fibres," Mater Des, vol.33, pp. 42-55, 2012.

[15] X. Sun, K. Zhao, Y. Li, R. Huang, Z. Ye, Y. Zhang, J. Ma, "A study of strain-rate effect and fiber reinforcement effect on dynamic behavior of steel fiber reinforced concrete," Constr. Build. Mater, vol. 158, pp. 657-669, 2018.

[16] X. Hou, S. Cao, Q. Rong, W. Zheng, G. Li, "Effects of steel fiber and strain rate on the dynamic compressive stress-strain relationship in reactive powder concrete," Constr. Build. Mater. vol. 170, pp. 570-581, 2018.

[17] Q. Li, X. Zhao, S. Xu, X. Gao, "Influence of steel fiber on dynamic compressive behavior of hybrid fiber ultra-high toughness cementitious composites at different strain rates," Constr. Build. Mater. vol. 125, pp. 490-500, 2016.

[18] Y. Su, J. Li, C. Wu, P. Wu, Z. Li, "Influences of nano-particles on dynamic strength of ultra-high-performance concrete," Compos. B Eng. vol. 91, pp. 595-609, 2016.

[19] L. D. Bertholf, C. H. Karnes, "Two-dimensional analysis of the split Hopkinson pressure bar system," J Mech Phys Solids, vol. 23, pp. 1-19, 1975.

[20] J. B. Mander, M. J. N. Priestley, R. Park, "Theoretical stress-strain model for confined concrete," J Struct Eng ASCE, vol. 114, pp. 1804-26, 1988.

[21] U. S. Lindholm, "Some experiments with the split Hopkinson pressure bar," J Mech Phys Solids, vol. 12, pp. 317-335, 1964.

[22] D. J. Frew, M. J. Forrestal, W. Chen, "Pulse shaping techniques for testing brittle materials with a split Hopkinson pressure bar," Exp Mech, vol. 42, no. 1, pp. 93-106, 2002.

[23] D. Feng, K. Xia, T. Lizhong, "Rate dependence of the flexural tensile strength of Lauren tian granite," Int J Rock Mech M in Sci, vol. 47 , no. 3 , pp. 469-475, 2010. 
[24] Z. Xu, H. Hao, H. N. Li, "Experimental study of dynamic compressive properties of fibre reinforced concrete material with different fibres." Mater Des, vol. 33, pp. 42-55, 2012.

[25] Y. Hao, H. Hao, "Dynamic compressive behaviour of spiral steel fibre reinforced concrete in split Hopkinson pressure bar tests," Construction and Building Materials, vol. 48, pp. 521-532, 2013.

[26] P. Challenor, R. Hankin, R. Marsh, Avoiding Dangerous Climate Change, Cambridge, UK: Cambridge University Press; 2006 [Ch. Achieving robust design from computer simulations, pp. 55-63.

[27] F. A. DiazDelaO, S. Adhikari, "Structural dynamic analysis using Gaussian process emulators," Eng Compute, vol. 27, no. 5, pp. 580-605, 2010

[28] T. E. Fricker, J. E. Oakley, N. D. Sims, K. Worden, "Probabilistic uncertainty analysis of an FRF of a structure using a Gaussian process emulator," Mech Syst Signal Process, vol. 25, no. 8, pp. 2962-75, 2011.

[29] Y. Xiong, W. Chen, D. Appley, X. Ding, "A non-stationary covariance-based kriging method for meta modelling in engineering design," Int J Numer Methods Eng, vol. 71, pp. 733-56, 2006

[30] J. Oakley, "Bayesian uncertainty analysis for complex computer codes," PhD thesis, University of Sheffield, 1999.
[31] J. Loeppky, J. Sacks, W. Welch, "Choosing the sample size of a computer experiment: a practical guide," Technimetrics, vol. 51, pp. 366-376, 2009.

[32] L. S. Bastos and A. O'Hagan, "Diagnostics for gaussian process emulators," Technometrics, vol. 51, no. 4, pp. 425-438, 2009.

Copyright (C) 2020 by the authors. This is an open access article distributed under the Creative Commons Attribution License (CC BY-NC-ND 4.0), which permits use, distribution and reproduction in any medium, provided that the article is properly cited, the use is non-commercial and no modifications or adaptations are made.

Qiong-Li Wang is currently a Ph.D. student in the Institute for Risk and Uncertainty, Department of Engineering, University of Liverpool in the UK.

F. A. DiazDelaO is a senior lecturer in the Institute for Risk and Uncertainty, Department of Engineering, University of Liverpool in the UK. $\mathrm{He}$ is an applied mathematician working on computational Bayesian methods, model calibration and meta-modelling. 